\title{
Target product profiles for protecting against outdoor malaria transmission
}

\author{
Gerry F Killeen ${ }^{1,2^{*}}$ and Sarah J Moore ${ }^{1,3}$
}

\begin{abstract}
Background: Long-lasting insecticidal nets (LLINS) and indoor residual sprays (IRS) have decimated malaria transmission by killing indoor-feeding mosquitoes. However, complete elimination of malaria transmission with these proven methods is confounded by vectors that evade pesticide contact by feeding outdoors.

Methods: For any assumed level of indoor coverage and personal protective efficacy with insecticidal products, process-explicit malaria transmission models suggest that insecticides that repel mosquitoes will achieve less impact upon transmission than those that kill them outright. Here such models are extended to explore how outdoor use of products containing either contact toxins or spatial repellents might augment or attenuate impact of high indoor coverage of LLINs relying primarily upon contact toxicity.

Results: LLIN impact could be dramatically enhanced by high coverage with spatial repellents conferring nearcomplete personal protection, but only if combined indoor use of both measures can be avoided where vectors persist that prefer feeding indoors upon humans. While very high levels of coverage and efficacy will be required for spatial repellents to substantially augment the impact of LLINs or IRS, these ambitious targets may well be at least as practically achievable as the lower requirements for equivalent impact using contact insecticides.
\end{abstract}

Conclusions: Vapour-phase repellents may be more acceptable, practical and effective than contact insecticides for preventing outdoor malaria transmission because they need not be applied to skin or clothing and may protect multiple occupants of spaces outside of treatable structures such as nets or houses.

Keywords: integrated vector management, pesticide, Anopheles, Plasmodium, transmission dynamics

\section{Background}

Long-lasting insecticidal nets (LLINs) and indoor residual spraying (IRS) have dramatically reduced malaria transmission by indoor-feeding (endophagic) mosquito populations in recent years [1-4]. However, elimination of transmission is not currently considered possible without cost-effective new technologies that protect against the persistent outdoor-biting (exophagic) vectors that continue to mediate self-sustaining residual transmission [4-6] because they are less vulnerable to insecticides applied to indoor surfaces [7-9]. Now that LLINs and IRS are being successfully scaled up in many countries across the tropics [10], it is timely to consider the potential of complementary products capable of

\footnotetext{
* Correspondence: gkilleen@ihi.or.tz

'Biomedical and Environmental Thematic Group, Ifakara Health Institute, PO Box 53, Ifakara, Morogoro, United Republic of Tanzania

Full list of author information is available at the end of the article
}

protecting humans against these residual vector populations while outside of their houses.

While mosquitocidal vaccines [11] and drugs [12] offer the exciting possibility of around-the-clock protection, wherever and whenever users are exposed, these products require systemic administration to humans and are in relatively early stages of development and evaluation as malaria vector control tools. In contrast, the most immediately available options simply extend coverage of safe, widely-used pyrethroid insecticides beyond the house by formulating them as treatments for clothing $[13,14]$. Alternatively, some fluorinated pyrethroids are far more volatile than the active ingredients currently used for LLINs and IRS so that emanators can deliver them to protected spaces in vapour phase, even where no treatable surface exists $[15,16]$.

However, it is crucial to clearly distinguish between alternative modes of action of vector control products

\section{Biomed Central}


and assess their potential comparative value for preventing malaria. Pesticide products either deter insects away from protected houses, sleeping spaces and humans, or they kill those that make physical contact with them [17]. While repellency or deterrence obviously enhances personal or household protection by LLINs or IRS, recently developed process-explicit models $[8,18]$ support field observations [19-21] that it may also attenuate the even greater community-wide protection that can be achieved by high coverage of products with contact toxicity $[22,23]$. This is because mosquitoes are not killed outright and may therefore be diverted to nearby community members, some of whom are unprotected nonusers [8]. It is, therefore, essential to consider the subtle mechanisms of action of spatial repellents, and their potential practicality, when assessing how much control of outdoor malaria transmission could be achieved in comparison with mosquito-toxic insecticides [13,14], vaccines [11] or drugs [12] that directly kill mosquitoes but require physical contact with the human user.

\section{Methods}

Existing models of the interaction between contrasting deterrent and toxic properties $[8,18]$ assume that these are combined in a single protected indoor space. Here these models [8] are extended to consider products with the following profiles used singly or in combination: 1) an LLIN conferring contact fast-acting toxicity that can only be used indoors, 2) an equivalent contact toxic product that can be only be used outdoors, 3) a spatial repellent product that is exclusively used outdoors or 4) a spatial repellent that is used both indoors and outdoors. The impact of these measures was expressed in terms of the relative risk of exposure to transmission $(\psi)$, calculated as the predicted entomological inoculation rate (EIR) experienced by humans (h) in a given scenario $(\Omega)$ of coverage and efficacy for these measures $\left(E_{\mathrm{h}, \Omega}\right)$ compared with that predicted under baseline conditions $\left(\mathrm{EIR}_{\mathrm{h}, \mathrm{0}}\right)$ where neither measure was in place:

$$
\psi_{\Omega}=\mathrm{EIR}_{\mathrm{h}, \Omega} / \mathrm{EIR}_{\mathrm{h}, 0}
$$

This term was calculated for unprotected individuals lacking either of these measures $\left(\psi_{\mathrm{h}, 0, \Omega}\right)$ or as a community-wide average, reflecting the coverage-weighted mean of such non-users and users of one or both measures $\left(\psi_{\mathrm{h}, \Omega}\right)$ [8]. For simplicity, only the communitywide average relative exposure and relative residual exposure for each scenario, reflecting combined community-level and personal protection effects, are presented in the main text in Figures 1, 2, 3). For comparison, equivalent plots of relative exposure and relative residual exposure of non-users, reflecting community-level protection effects only, are available online (See Additional file 1, Additional file 2, and Additional file 3).
In all cases, coverage levels of $80 \%$ were assumed for both the indoor and outdoor protection measures, consistent with current global targets for LLINs and IRS [24], and two distinct Afrotropical vector population scenarios were examined: strongly anthropophagic Anopheles gambiae, which rarely uses cattle as alternative non-human hosts, and zoophagic Anopheles arabiensis, which does where they are available. These relative exposure outcomes $(\psi)$ were predicted as a function of the mean proportion of malaria transmission exposure of a non-user of any measure which occurs indoors $\left(\pi_{i}\right)[9,25,26]$ and the personal protective efficacy $(\rho)$ arising from increased deterrence $\left(\theta_{\Delta}\right)$ or pre-feed mortality $\left(\theta_{\mu, \text { pre }}\right)$ of mosquitoes attacking users of the product [8]. While this model can just as readily simulate the impact of IRS, only LLINs were considered as a potential means of indoor protection because the combination of the physical barrier or the net and the fast-acting toxicity of their pyrethroid active ingredients allow them to be directly compared with spatial repellents or insecticidal clothing that also confer direct personal or household protection [27]. By comparison, many IRS formulations are relatively slow-acting, usually killing mosquitoes after they have fed, so that the comparison between repellent and toxic modes of action is confounded by the differences between slow and fast-acting toxins $[8,27]$. Therefore, no scenarios including IRS as the indoor protection measure were simulated. Further details of the extended model and its application in this report are available online (See Additional file 4).

\section{Results}

LLINs depend upon high proportions of human exposure occurring indoors to achieve maximum impact upon malaria transmission (Figure 1). Note that the apparent lack of impact of indoor LLIN use where mosquitoes prefer to feed outdoors should be interpreted cautiously. It is critical to determine whether these behavioural characteristics reflect historical baseline values consistent with those observed before these indoor control measures were introduced, rather than modified transmission patterns associated with residual vector populations after intervention scale up [4-6]. Indoor use of such insecticidal products may have little value where no major indoor-biting vectors have historically existed or where they have been successfully eliminated. However, contemporary observations of high proportions of outdoor exposure can simply reflect successful suppression of previously abundant endophagic populations [4-6,28-31], that can readily recover and restore high transmission levels if coverage with LLINs is not sustained.

Exclusive outdoor use of products that either kill or repel mosquitoes consistently complements LLINs (Figure 1) by filling the protective coverage gap that occurs 


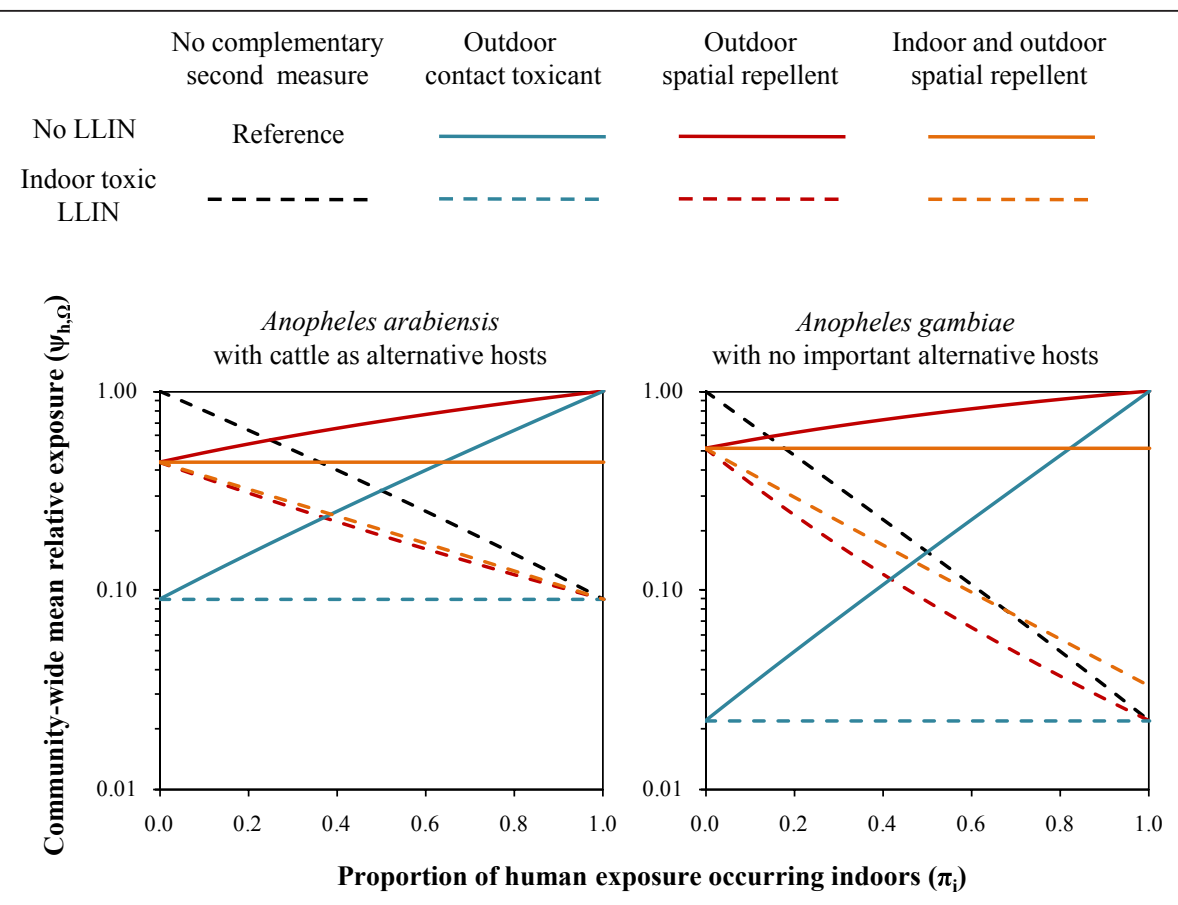

Figure 1 Impact of products for outdoor malaria prevention expressed in terms of the mean relative risk of exposure experienced by the average community member $\left(\psi_{\mathrm{h}, \Omega}\right)$. Scenarios are considered in which LLIN products that provide $50 \%$ personal protection ( $\left.\rho_{\mathrm{i}}=0.5\right)$ by killing half of all mosquitoes that attack them $\left(\theta_{\mu, \text { pre, }}=0.5\right)$ are complemented by use of additional products conferring equivalent personal protection ( $\rho_{\circ}$ or $\rho_{i+o}=0.5$ ) with one of the three following profiles: Products for exclusively outdoor use that kill attacking mosquitoes before they feed $\left(\theta_{\mu, \text { pre, }}=0.5\right)$ or products that deter mosquitoes from attacking that are used either outdoors only $\left(\theta_{\Delta, 0}=0.5\right)$ or are used both indoors and outdoors $\left(\theta_{\Delta, \mathrm{i}+\mathrm{O}}=0.5\right)$. Further details of the model and symbol definitions are available online (See Additional file 4)

in the rural tropics where people commonly spend their evenings outside. In stark contrast with the effects of supplementing toxicity with repellency within a single product applied in the same place [8], where at least half of transmission occur outdoors $\left(0.5 \leq \pi_{\mathrm{i}}\right)$, spatial repellents applied outdoors consistently supplement the impact of indoor toxins (Figure 2). In fact, spatial repellents even synergize with LLINs for anthropophagic vectors (Figure 2), with an optimum where transmission occurs both indoors and outdoors $\left(0.2<\pi_{\mathrm{i}}<0.8\right)$ because mosquitoes diverted from outdoor repellent users may subsequently attack those protected indoors by lethal LLINs (See Additional file 1 and Additional file 2). Conversely, if repellents are also used indoors in settings where LLINs are common, mosquitoes can be deterred from exposure to fatal contact with products so that overall protection is attenuated where most transmission occurs indoors $\left(\pi_{\mathrm{i}}>0.7\right)$ and vectors rarely feed upon non-human blood sources (Figures 1 and 2). Such conditions would necessitate the avoidance of combined indoor use of spatial repellents alongside LLINs for the former to augment the communal protection already achieved by the latter. This caveat even applies to settings where residual transmission following LLINs scale-up is dominated by exophagic or zoophagic mosquitoes [1,4-6]. Except in unusual cases where they have been irreversibly eliminated from isolated islands [4], historically important endophagic and anthropophagic mosquito populations may well recover if spatial repellents are introduced to houses already using LLINs so that sub-lethal exposure to the former undermines the degree of lethal exposure to the latter.

Contact toxins appear superior to spatial repellents at any given level of coverage and personal protective efficacy (Figure 3). However, significant practical obstacles may render high efficacy and coverage targets more difficult to achieve with contact toxins applied to humans while outdoors. Protection of the entire vulnerable skin surface with either clothing or topical applications may be unrealistic in most tropical settings. Regular bathing, as well as washing and ironing of clothing, present significant barriers to high coverage with contact toxins in many societies. Furthermore, high coverage may be as difficult to achieve as durable high efficacy because user acceptance obviously depends on perceived personal protection. Subsequent simulations therefore examined and compared the relationship between impact and protective efficacy for these two distinct modes of action.

While spatial repellents are predicted to confer useful, but nevertheless limited levels of community-level 


\section{Outdoor Outdoor Indoor and outdoor contact toxicant spatial repellent spatial repellent}

As sole measure

Incremental effect as a supplement to indoor toxic LLIN

Line of equivalence of combination with LLIN alone

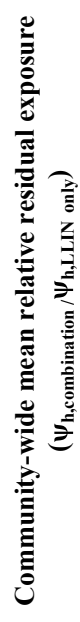

Anopheles arabiensis with cattle as alternative hosts

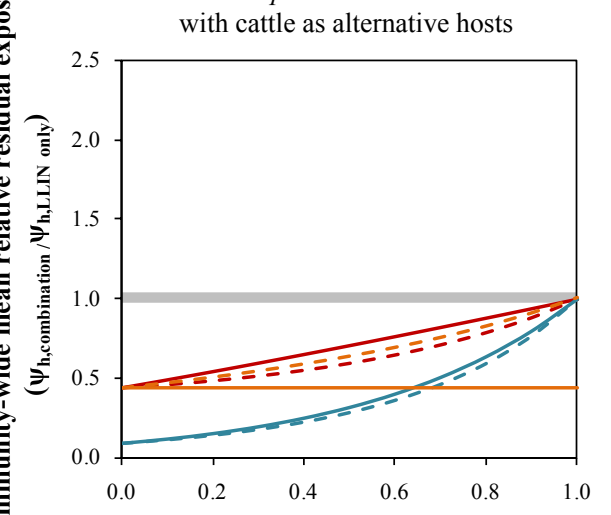

Anopheles gambiae with no important alternative hosts

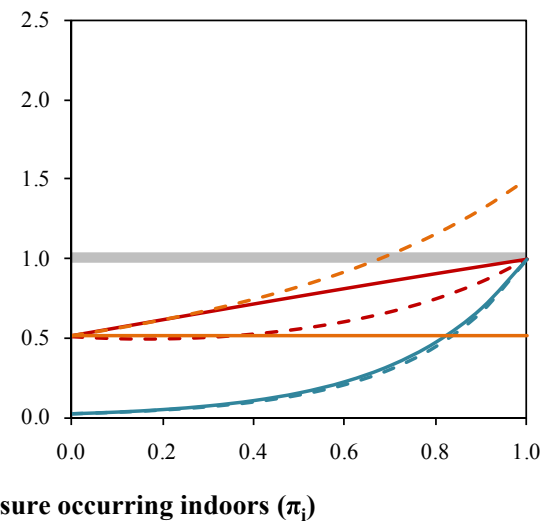

Figure 2 Additional incremental impact of outdoor contact toxins $\left(\theta_{\mu, p r e, o}=0.5\right)$ or repellents that are exclusively used outdoors $\left(\theta_{\Delta, o}\right.$ $=0.5)$ or used both indoors and outdoors $\left(\theta_{\Delta, i+o}=0.5\right)$ when combined with indoor LLINs with contact toxins $\left(\theta_{\mu, p r e, i}=0.5\right)$, compared with their direct impact as stand-alone intervention strategies. Impact is expressed in terms of the mean relative risk of exposure to residual transmission for the average community member where LLINS are combined with additional products with the above profiles $\left(\psi_{h, \text { combination }}\right)$ compared with when they are applied as a stand-alone measure $\left(\psi_{h, L L I N s}\right.$ alone). All products are assumed to confer $50 \%$ personal protection ( $\rho_{\circ}$ or $\rho_{i+o}=0.5$ ) by either repelling or killing half of all mosquitoes that attack them $(\theta=0.5)$. Further details of the model and symbol definitions are available online (See Additional file 4)

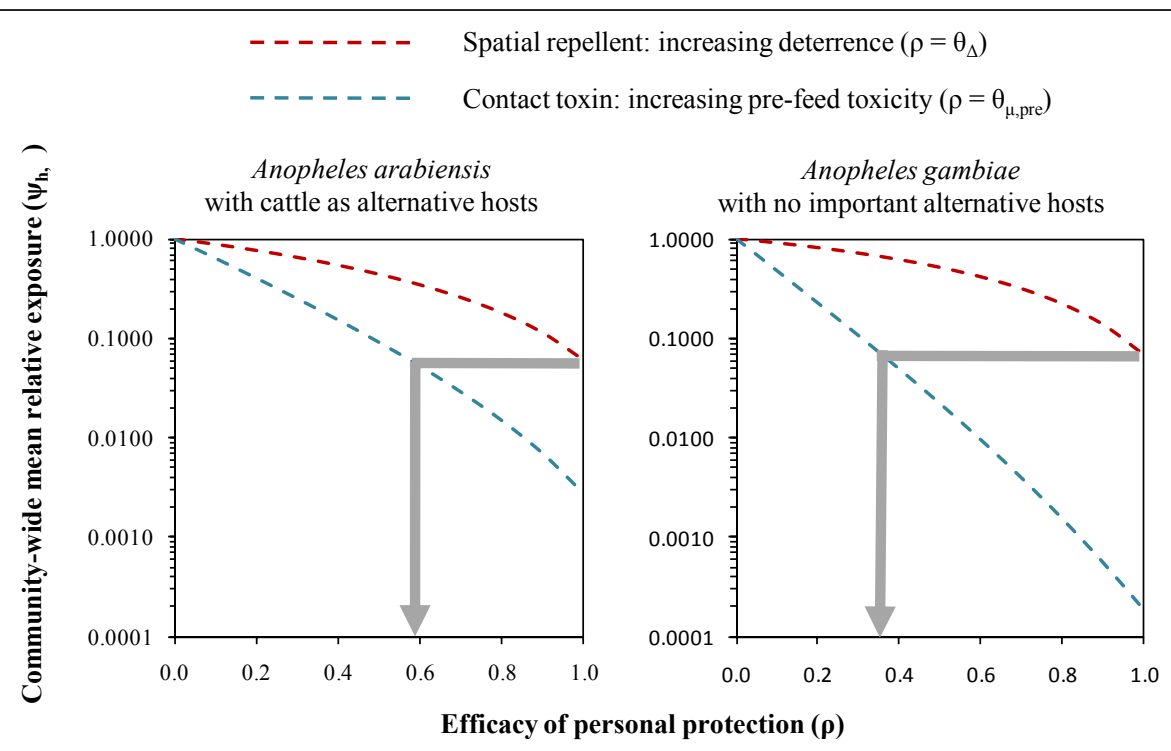

Figure 3 Progressive impact upon a completely outdoor transmission system $\left(\pi_{i}=0\right)$ of products with increasing efficacy of personal protection $\left(\rho_{0}\right)$ achieved by either repelling $\left(\theta_{\Delta, 0}\right)$ or killing $\left(\theta_{\mu, p r e, o}\right)$ attacking mosquitoes before they feed upon human users. The grey arrows represent interpolation of the efficacy thresholds at which the toxic mode of action achieves equivalent transmission control to the theoretical limit at complete protective efficacy $\left(\theta_{\Delta, \mathrm{o}}=1.0\right.$ so $\left.\rho_{\circ}=1.0\right)$ for spatial repellents at high coverage $\left(C_{h}=0.8\right)$. Impact is expressed in terms of the mean relative risk of exposure experienced by the average community member $\left(\psi_{\mathrm{h},}, \Omega\right)$. Further details of the model and symbol definitions are available online (See Additional file 4) 
protection (See Additional file 3), this may be complemented by high levels of personal protection to achieve far greater overall impact (Figure 3). Measures relying on contact toxins would need to kill between 36 and $56 \%$ of mosquitoes that attack protected users to match the expected benefits of high coverage with a spatial repellent conferring near-complete protective efficacy (Figure 3). Such levels of efficacy for contact insecticides are approximately equivalent to those observed for LLINs products that have been washed or undergone long periods of regular use [27] and may be more challenging to achieve in the absence of such a near-complete protective barrier as a net.

\section{Discussion}

Despite their apparent theoretical inferiority to contact toxins, there are several practical reasons why spatial repellents, that protect a space rather than a surface [32] may be equally useful for preventing outdoor transmission of malaria and other mosquito-borne pathogens.

While contact irritants have no obvious practical advantage over contact toxins, vapour-phase repellents may be more acceptable and practical for outdoor use because they do not need to be applied to the skin or clothing of active humans when they are outside of treatable structures such as nets or houses. Pesticides that are volatile enough to diffuse through air negate the need to treat the skin or clothing and can protect a space surrounding a delivery point so that a single unit can protect multiple users for long periods [15] without requiring regular re-application or unrealistic levels of user compliance [33].

The hypothesis that outdoor malaria transmission can be controlled effectively with either contact insecticides or spatial repellents can only be tested through rigorous field evaluations of products that match the corresponding target product profiles suggested by these simulations. While vaccines [11] and drugs [12] that render human blood toxic to mosquitoes represent exciting possibilities for the future, permethrin-treated clothing $[13,14]$ offers the closest existing approximation to the target product profile predicted for outdoor use of contact insecticides. For spatial repellents, it is encouraging that products matching the ambitious efficacy targets predicted here [15], exciting leads for new active ingredients [34,35], and creative delivery methods that restrict use to waking hours when people are usually outside [16], have all been described.

In summary, formulations of either contact insecticides or spatial repellents currently appear to have equal potential for preventing, or even eliminating, outdoor malaria transmission. Protection against indoor-biting malaria mosquitoes with LLINs or IRS is becoming a norm across growing tracts of the tropics. It is, therefore, time to prioritize development and field evaluation of new products designed specifically to tackle malaria transmission occurring outside of treatable structures such as walls, roofs or nets.

\section{Additional material}

\begin{abstract}
Additional file 1: Figure S1. Purely community-level impact of products for outdoor malaria prevention expressed in terms of the mean relative risk of exposure experienced by non-users of any protective measure.

Additional file 2: Figure S2. Additional incremental community-level impact of outdoor contact toxins or repellents that are exclusively used outdoors or used both indoors and outdoors when combined with indoor LLINs with contact toxins, compared with their direct impact as stand-alone intervention strategies.

Additional file 3: Figure S3. Progressive community-level impact upon a completely outdoor transmission system of products with increasing efficacy of personal protection achieved by either repelling or killing attacking mosquitoes before they feed upon human users.

Additional file 4: Supplemental methods S4. Detailed model description.
\end{abstract}

\section{Acknowledgements}

This work was financially supported by the Bill \& Melinda Gates Foundation (Award number 51431). We also thank Dr J Greico, Dr Nicole Achee, Dr Kate Aultman, Dr Tanya Russell, Dr Tom Burkot, and Dr Nakul Chitnis for many insightful discussions and Dr Paul Smithson, Dr David Malone, Dr Robert Sloss and Mr Peter Sangoro for their comments on the manuscript.

\section{Author details}

${ }^{1}$ Biomedical and Environmental Thematic Group, Ifakara Health Institute, PO Box 53, Ifakara, Morogoro, United Republic of Tanzania. ${ }^{2}$ Vector Group, Liverpool School of Tropical Medicine, Pembroke Place, Liverpool L3 5QA, UK. ${ }^{3}$ Department of Disease Control, London School of Hygiene and Tropical Medicine, Keppel Street, London WC1E 7HT, UK.

\section{Authors' contributions}

Both authors formulated the research questions and developed the conceptual basis of the model. GFK drafted the model formulation and manuscript, which was then critiqued and edited by SJM. All authors have read and approved the final version of the manuscript.

\section{Competing interests}

While this study was independently funded by the Bill \& Melinda Gates Foundation, both authors have received funding support for other research projects from manufactures of insecticidal public health products:

Vestergaard Frandsen SA (GFK), Syngenta (SJM), Pinnacle Development (SJM) and SC Johnson (SJM).

Received: 8 November 2011 Accepted: 11 January 2012

Published: 11 January 2012

\section{References}

1. Bayoh MN, Mathias DK, Odiere MR, Mutuku FM, Kamau L, Gimnig JE, Vulule JM, Hawley WA, Hamel MJ, Walker ED: Anopheles gambiae: historical population decline associated with regional distribution of insecticide-treated bed nets in western Nyanza Province Kenya. Malar $J$ 2010, 9:62.

2. Russell TL, Lwetoijera DW, Maliti D, Chipwaza B, Kihonda J, Charlwood JD, Smith TA, Lengeler C, Mwanyangala MA, Nathan R, Knols BGJ, Takken W, Killeen GF: Impact of promoting longer-lasting insecticide treatment of bednets upon malaria transmission in a rural Tanzanian setting with pre-existing high coverage of untreated nets. Malar J 2010, 9:187.

3. Meyrowitsch DW, Pedersen EM, Alifrangis M, Scheike TH, Malecela MN, Magesa SM, Derua YA, Rwegoshora RT, Michael E, Simonsen PE: Is the 
current decline in malaria burden in sub-Saharan Africa due to a decrease in vector population? Malar J 2011, 10:188.

4. Bugoro H, Cooper RD, Butafa C, Iro'ofa C, Mackenzie DO, Chen CC, Russell TL: Bionomics of the malaria vector Anopheles farauti in Temotu Province, Solomon Islands: issues for malaria elimination. Malar J 2011, 10:133.

5. Russell TL, Govella NJ, Azizi S, Drakeley CJ, Kachur SP, Killeen GF: Increased proportions of outdoor feeding among residual malaria vector populations following increased use of insecticide-treated nets in rural Tanzania. Malar J 2011, 10:80.

6. Reddy M, Overgaard HJ, Abaga S, Reddy VP, Caccone A, Kiszewski AE, Slotman MA: Outdoor host seeking behaviour of Anopheles gambia mosquitoes following initiation of malaria vector control on Bioko Island Equatorial Guinea. Malar J 2011, 10:184.

7. Griffin JT, Hollingsworth TD, Okell LC, Churcher TS, White M, Hinsley W, Bousema T, Drakeley CJ, Ferguson NM, Basáñez MG, Ghani AC: Strategies towards Plasmodium falciparum malaria elimination in Africa using currently available tools. PLoS Med 2010, 7:e1000324.

8. Killeen GF, Chitnis N, Moore SJ, Okumu FO: Target product profile choices for intra-domiciliary malaria vector control pesticide products: repel or kill? Malar J 2011, 10:207.

9. Govella NJ, Okumu FO, Killeen GF: Insecticide-treated nets can reduce malaria transmission by mosquitoes which feed outdoors. Am J Trop Med Hyg 2010, 82:415-419.

10. WHO: World Malaria Report Geneva: World Health Organization; 2010.

11. Foy BD, Magalhaes T, Injera WE, Sutherland I, Devenport M, Thanawastien A, Ripley D, Cardenas-Freytag L, Beier JC: Induction of mosquitocidal activity in mice immunized with Anopheles gambia midgut cDNA. Infect Immun 2003, 71:2032-2040.

12. Sylla M, Kobylinski KC, Gray M, Chapman PL, Sarr MD, Rasgon JL, Foy BD: Mass drug administration of ivermectin in south-eastern Senegal reduces the survivorship of wild-caught, blood fed malaria vectors. Malar J 2010, 9:365.

13. Macintyre K, Sosler S, Letipila F, Lochigan M, Hassig S, Omar SA, Githure J: A new tool for malaria prevention? Results of a trial of permethrinimpregnated bedsheets (shukas) in an area of unstable transmission. Int J Epidemiol 2003, 32:157-160.

14. Kimani EW, Vulule JM, Kuria IW, Mugisha F: Use of insecticide-treated clothes for personal protection against malaria: a community trial. Malar J 2006, 5:63.

15. Kawada H, Maekawa Y, Takagi M: Field trial on the spatial repellency of metofluthrin-impregnated plastic strips for mosquitoes in shelters without walls (beruga) in Lombok, Indonesia. J Vector Ecol 2005, 30:181-185.

16. Pates HV, Line JD, Keto AJ, Miller JE: Personal protection against mosquitoes in Dar es Salaam, Tanzania, by using a kerosene oil lamp to vaporize transfluthrin. Med Vet Entomol 2002, 16:277-284.

17. Grieco JP, Achee NL, Chareonviriyaphap T, Suwonkerd W, Chauhan K, Sardelis MR, Roberts DR: A new classification system for the actions of IRS chemicals traditionally used for malaria control. PLoS One 2007, 2:e716.

18. Yakob L, Dunning R, Yan G: Indoor residual spray and insecticide-treated bednets for malaria control: theoretical synergisms and antagonisms. J $R$ Soc Interface 2010, 8:799-806.

19. Kouznetsov RL: Malaria control by application of indoor spraying of residual insecticides in tropical Africa and its impact on community health. Trop Doct 1977, 7:81-93.

20. Muirhead-Thomson RC: The significance of irritability, behaviouristic avoidance and allied phenomena in malaria eradication. Bull World Health Organ 1960, 22:721-734.

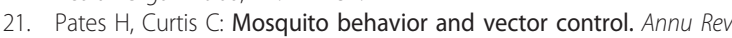
Entomol 2005, 50:53-70.

22. Hawley WA, Phillips-Howard PA, ter Kuile FO, Terlouw DJ, Vulule JM, Ombok M, Nahlen BL, Gimnig JE, Kariuki SK, Kolczak MS, Hightower AW: Community-wide effects of permethrin-treated bednets on child mortality and malaria morbidity in western Kenya. Am J Trop Med Hyg 2003, 68(Supplement 4):121-127.

23. Killeen GF, Smith TA, Ferguson HM, Abdulla S, Mshinda H, Lengeler C, Kachur SP: Preventing childhood malaria in Africa by protecting adults from mosquitoes with insecticide-treated nets. PLoS Med 2007, 4:e229.

24. WHO: Insecticide treated mosquito nets: a position statement. Geneva: Global Malaria Programme; World Health Organization; 2007, 10.
25. Garrett-Jones C: A method for estimating the man-biting rate. Geneva: World Health Organization; 1964, 22 [http://whqlibdoc.who.int/malaria/ WHO_Mal_450.pdf].

26. Elliott R: Studies on man-vector contact in some malarious areas in Colombia. Geneva: World Health Organization; 1967, 32 [http://whqlibdoc who.int/malaria/WHO_Mal_67.627.pdf].

27. Okumu FO, Moore SJ: Combining indoor residual spraying and insecticide-treated nets for malaria control in Africa: a review of possible outcomes and an outline of suggestions for the future. Malar J 2011, 10:208.

28. Gillies MT, Smith A: Effect of a residual house-spraying campagn on species balance in the Anopheles funestus group: the replacement of Anopheles gambiae Giles with Anopheles rivulorum Leeson. Bull Entomol Res 1960, 51:248-252.

29. Gillies MT, Furlong M: An investigation into the behaviour of Anopheles parensis Gillies at Malindi on the coast of Kenya. Bull Entomol Res 1964, 55:1-16.

30. Gillies MT: A new species of the Anopheles funestus complex (Diptera: Culicidae) from East Africa. Proc Roy Ent Soc London (B) 1962, 31:81-86.

31. Gillies MT, DeMeillon B: The Anophelinae of Africa South of the Sahara (Ethiopian zoogeographical region) Johannesburg: South African Institute for Medical Research; 1968.

32. Strickman D: Area Repellents. In In Insect Repellents: principles, methods, and use. Edited by: Debboun M, Frances SP, Strickman D. Boca Raton: CRC Press; 2006:.

33. Cobelens FG, Leentvaar-Kuijpers A: Compliance with malaria chemoprophylaxis and preventative measures against mosquito bites among Dutch travellers. Trop Med Int Health 1997, 2:705-713.

34. Turner SL, Li N, Guda T, Githure J, Cardé RT, Ray A: Ultra-prolonged activation of $\mathrm{CO}_{2}$-sensing neurons disorients mosquitoes. Nature 2011, 474:87-92.

35. Jones PL, Paska GM, Rinker DC, Zwiebel LJ: Functional agonism of insect odorant receptor ion channels. Proc Natl Acad Sci USA 2011, 108:8821-8825.

doi:10.1186/1475-2875-11-17

Cite this article as: Killeen and Moore: Target product profiles for protecting against outdoor malaria transmission. Malaria Journal 2012 11:17.

\section{Submit your next manuscript to BioMed Central and take full advantage of:}

- Convenient online submission

- Thorough peer review

- No space constraints or color figure charges

- Immediate publication on acceptance

- Inclusion in PubMed, CAS, Scopus and Google Scholar

- Research which is freely available for redistribution

Submit your manuscript at www.biomedcentral.com/submit
C Biomed Central 